\title{
CELL PHONE RINGTONE, BUT NOT LANDLINE PHONE RINGTONE, AFFECTS COMPLEX REACTION TIME
}

\author{
RADOSŁAW ZAJDEL ${ }^{1}$, JUSTYNA ZAJDEL ${ }^{2}$, JANUSZ ŚMIGIELSKI ${ }^{1}$ and DARIUSZ NOWAK ${ }^{3}$ \\ ${ }^{1}$ Medical University of Lodz, Łódź, Poland \\ Department of Medical Informatics and Statistics, Faculty of Health Sciences \\ ${ }^{2}$ Medical University of Lodz, Łódź, Poland \\ Department of Medical Law, Chair of Humanities \\ ${ }^{3}$ Medical University of Lodz, Łódź, Poland \\ Chair of Experimental and Clinical Physiology
}

\begin{abstract}
Introduction: Legislation systems of most countries prohibited using the handheld mobile phone while driving due to the fact that it disturbs concentration and causes hand involvement. Every phone owner is accustomed to the ringtone of his phone and almost involuntarily endeavors to pick it up or check who calls. This engages one's psychomotor skills, which in our opinion contributes to the attenuation of reaction time needed for performing other crucial functions. Objectives: The aim of the study was: (1) to evaluate the influence of the sound of a ringing mobile phone on the complex reaction time (RT) score in healthy subjects (owners), and (2) to check if there are any differences in RT when a landline phone and mobile phone ring. Methods: To assess RT we used our system and protocol of examination, previously validated. The examination conditions were standardized. All tests were performed in the same room with the same light and general acoustic conditions. The test group consisted of 23 women and 24 men, aged 19-24 years. The examination comprised 4 sessions: Training Session (TS) during which the subjects were accustomed with the application and sample stimuli, Control Session (CS) with no telephone ringing, Landline Session (LS) with landline phone ringing, Mobile Session (MS) with mobile phone ringing. Results: The median RT in the study population was significantly elongated $(\mathrm{p}<0.001)$ in MS. In women and in men RTs were significantly longer in MS than in CS and non-significantly longer than in LS. Reaction times in CS, LS and MS were longer in women, however the differences were not significant $(\mathrm{p}>0.05)$. Conclusions: We think that the specific 'bond' between a person and their private phone can significantly disrupt their attention and thus affect the attention-demanding activities.
\end{abstract}

Key words:

Complex reaction time, Mobile phone, Landline phone, Gender psychomotoric differences

\section{INTRODUCTION}

Although our inseparable companion, a cell phone is not always our ally. As a source of noise and distraction, it disturbs our concentration not only while making a call, but already when it rings. It appears that a well-known noise source can result in the deterioration of our attention level even more than exposure to other, unfamiliar sounds. This is a peculiar disadvantage, since we keep our phones always handy, not only while resting, but in situations requesting undivided attention, for example while driving. We analyzed reaction time of the tested subjects in tests involving a ringing cell phone belonging to a given subject

Received: February 27, 2012. Accepted: October 10, 2012.

Address reprint request to R. Zajdel, Department of Medical Informatics and Statistics, Medical University of Lodz, Pl. Hallera 1, 90-647 Łódź, Poland (e-mail: radoslaw.zajdel@umed.lodz.pl). 
versus a landline phone (as a foreign sound source). We noted a statistically longer reaction time for the subjectowned cell phone. The reaction time depended on gender. It was longer in the females then in the males. No correlation was found in the landline phone sessions.

Living in the world of the 21 century and submerged in the Western civilization, we are exposed to accelerating pace of life, shrinking leisure time and omnipresent noise. Taking advantage of many technical facilities, we put in danger the comfort of our lives. The cell phone that was supposed to provide an opportunity to contact help in case of emergency became our inseparable companion and reminds us about it in the most undesirable moments. Using cell phone while driving decreases the ability to concentrate and impairs attention [1-3]. Driving is a complex sensomotoric process, requiring simultaneous attention shifting, engagement of short- and long-term memory, ability to filter stimuli with consequent evaluation of their importance and to perform adequate complex reactions. It is also a psychological process with a wide spectrum of dependencies, including driving speed, road conditions, distance [1]. We decided to reduce the number of variables in this complex equation to get more explicit results and conclusions.

In spite of living in the environment full of various sounds, we are able to identify and isolate typically known sounds, noises and phrases. This makes us able to take adequate measures (known stimulus - trained response), but on the other hand it additionally attracts our attention and distracts us from current activities, which may result in the elongation of reaction time and eventually hinder the execution of specific tasks. The most significant factors are sound frequency, periodicity/repeatability and type (natural speech, artificial speech, melodious sounds) [2]. Therefore, it is a complex process relying on many factors, already on the level of inherent sound characteristics. It has been shown that the presence of additional signals and noise phenomena disturbing the flow in the two-way sensomotoric information channel has a negative effect on safety and ability to drive a car [2,3]. Cavanagh et al. revealed, using the multiple object-tracking paradigm, that a person can track only 3-5 items simultaneously [3]. In our study, we attempted to check whether the sound of a ringing phone disturbs the driver's complex reaction.

\section{OBJECTIVES}

The aim of the study was to evaluate the influence of sound produced by a ringing mobile phone on the complex reaction time (RT) score in healthy subjects (owners of the ringing phones). The second aim was to check if there are any differences in RT when a landline phone and mobile phone ring, the latter of which belonged to the tested subject.

\section{MATERIALS AND METHODS}

In our study, we analyzed reaction time in tests both without additional sound sources and with a phone ringing. The phone used was either a cell phone that belonged to the tested subject or a landline phone situated beside the test computer on the table. The sample group consisted of 23 females and 24 males aged 19-28 years. All of them were students and employees of the Medical University of Lodz, Poland. The students qualified for the study were not under the influence of any chemical substances; they had not drunk tea, coffee or other stimulating drinks for at least 12 hours before the examination and had slept well on the night prior to the experiment. None of the subjects included in the investigation had any complaints, suffered from any chronic illnesses or taken any medicines.

The study system comprised a dedicated software called Reactor, running on a regular personal computer equipped with a 17-inch LCD display monitor and a pair of consumer, good quality loudspeakers standing in stereo position. The Reactor program, designed and written by 
the first author of this paper, had been clinically evaluated and the results had been published previously [4,5].

Reactor allows to display a designed array of simple geometric figures - square, circle or triangle, filled with a color - on a computer screen in various colors and sizes, as well as to generate a short sound of given frequency produced by the loudspeakers. The researcher designs an examination by defining the number of stimuli, their shape, color, place of presentation on the screen as well as the frequency of produced sounds. One can also define the way in which the subject has to react to a designed stimuli. Every subject participated in four sessions of the test. The differences among the tests are described below. A single test comprised a set of 80 visual and/or acoustic stimuli. The total time of one stimulus including the break that followed it was $2 \mathrm{~s}$. The visual stimulus was displayed on the screen for $1100 \mathrm{~ms}$. The visual stimulus could be accompanied by a sound stimulus, starting with the visual stimulus and lasting $400 \mathrm{~ms}$. The acoustic stimulus could be presented separately $(400 \mathrm{~ms})$. A single test lasted $160 \mathrm{~s}$. The standard break between the consecutive presentations was $20 \mathrm{~s}$. The chosen shape of the visual stimulus in this study was a square $-480 \times 480 \mathrm{px}$, displayed in the very center of the monitor. The color of the square was a factor that differentiated the stimuli and the reaction type. The visual stimulus could be accompanied by a sound, or a sound could be presented alone. The Reactor program allows the researcher to choose the frequency of sound stimuli. In this study, we decided to use the same, standard frequency of $250 \mathrm{~Hz}$, which is well recognized by humans. The level of the presented sounds was $75 \mathrm{~dB}$, as described above. The detailed combination of stimuli is included in Table 1 . The choice of stimuli and the test design were performed arbitrarily by the authors of this paper. This technique had been successfully employed and assessed in our two previous studies [4,5].

The beginning of the examination was preceded by the LCD screen calibration. The calibration comprised color and
Table 1. Detailed description of the conducted tests*

\begin{tabular}{llcl}
\hline \multicolumn{2}{c}{ Visual } & Acoustic & \multicolumn{1}{c}{ Proper reaction } \\
No stimulus - & signal & \\
\multicolumn{2}{c}{ color } & (Hz) & \\
\hline 1 & yellow & & do nothing \\
2 & green & - & pressing the button in the left hand \\
3 & red & - & pressing the button in the right hand \\
4 & red & - & pressing the button in the right hand \\
5 & - & 250 & pressing the buttons in both hands \\
6 & blue & - & pressing the button in the left hand \\
7 & yellow & 250 & do nothing \\
8 & yellow & - & do nothing \\
9 & green & - & pressing the button in the left hand \\
10 & - & 250 & pressing the buttons in both hands \\
11 & green & - & pressing the button in the left hand \\
12 & red & - & pressing the button in the right hand \\
13 & red & 250 & do nothing \\
14 & yellow & - & do nothing \\
15 & yellow & - & do nothing \\
16 & green & - & pressing the button in the left hand \\
17 & red & - & pressing the button in the right hand \\
18 & - & 250 & pressing the buttons in both hands \\
19 & green & - & pressing the button in the left hand \\
20 & blue & - & pressing the button in the left hand \\
21 & red & - & pressing the button in the right hand \\
22 & yellow & - & do nothing \\
23 & - & 250 & pressing the buttons in both hands \\
24 & red & - & pressing the button in the right hand \\
25 & green & - & pressing the button in the left hand \\
26 & yellow & - & do nothing \\
27 & red & - & pressing the button in the right hand \\
28 & green & - & pressing the button in the left hand \\
29 & red & 250 & do nothing \\
30 & red & - & pressing the button in the right hand \\
31 & green & - & pressing the button in the left hand \\
32 & red & - & pressing the button in the right hand \\
& & 250 & pressing the buttons in both hands \\
& & & do nothing \\
& & & pressing the button in the left hand \\
\hline
\end{tabular}


Table 1. Detailed description of the conducted tests* - cont.

\begin{tabular}{|c|c|c|c|}
\hline & $\begin{array}{l}\text { Visual } \\
\text { stimulus - } \\
\text { color }\end{array}$ & $\begin{array}{c}\text { Acoustic } \\
\text { signal } \\
(\mathrm{Hz}) \\
\end{array}$ & Proper reaction \\
\hline 36 & yellow & - & do nothing \\
\hline 37 & green & 250 & do nothing \\
\hline 38 & - & 250 & pressing the buttons in both hands \\
\hline 39 & - & 250 & pressing the buttons in both hands \\
\hline 40 & blue & - & pressing the button in the left hand \\
\hline 41 & red & - & pressing the button in the right hand \\
\hline 42 & blue & - & pressing the button in the left hand \\
\hline 43 & red & 250 & do nothing \\
\hline 44 & yellow & - & do nothing \\
\hline 45 & green & - & pressing the button in the left hand \\
\hline 46 & blue & - & pressing the button in the left hand \\
\hline 47 & yellow & - & do nothing \\
\hline 48 & yellow & 250 & do nothing \\
\hline 49 & red & - & pressing the button in the right hand \\
\hline 50 & green & - & pressing the button in the left hand \\
\hline 51 & red & - & pressing the button in the right hand \\
\hline 52 & - & 250 & pressing the buttons in both hands \\
\hline 53 & green & - & pressing the button in the left hand \\
\hline 54 & yellow & - & do nothing \\
\hline 55 & blue & - & pressing the button in the left hand \\
\hline 56 & yellow & 250 & do nothing \\
\hline 57 & blue & 250 & do nothing \\
\hline 58 & green & - & pressing the button in the left hand \\
\hline 59 & yellow & - & do nothing \\
\hline 60 & blue & 250 & do nothing \\
\hline 61 & red & - & pressing the button in the right hand \\
\hline 62 & red & - & pressing the button in the right hand \\
\hline 63 & blue & 250 & do nothing \\
\hline 64 & yellow & 250 & do nothing \\
\hline 65 & green & - & pressing the button in the left hand \\
\hline 66 & yellow & - & do nothing \\
\hline 67 & - & 250 & pressing the buttons in both hands \\
\hline 68 & green & - & pressing the button in the left hand \\
\hline 69 & - & 250 & pressing the buttons in both hands \\
\hline 70 & red & - & pressing the button in the right hand \\
\hline 71 & green & - & pressing the button in the left hand \\
\hline
\end{tabular}

Table 1. Detailed description of the conducted tests* - cont.

\begin{tabular}{|c|c|c|c|}
\hline & $\begin{array}{c}\text { Visual } \\
\text { o stimulus - } \\
\text { color }\end{array}$ & $\begin{array}{c}\text { Acoustic } \\
\text { signal } \\
(\mathrm{Hz})\end{array}$ & Proper reaction \\
\hline 72 & blue & - & pressing the button in the left hand \\
\hline 73 & yellow & 250 & do nothing \\
\hline 14 & green & - & pressing the button in the left hand \\
\hline 75 & - & 250 & pressing the buttons in both hands \\
\hline 76 & red & - & pressing the button in the right hand \\
\hline 77 & yellow & - & do nothing \\
\hline 78 & red & - & pressing the button in the right hand \\
\hline 79 & blue & 250 & do nothing \\
\hline 80 & green & - & pressing the button in the left hand \\
\hline
\end{tabular}

* When green or blue color was presented, a subject was to press the button held in the left hand. When red color was presented, a subject was to press the button held in right hand. When yellow was presented or the visual stimulus was presented together with sound, the proper reaction was not to press anything.

brightness correction and was conducted using the Datacolor Spyder4 PRO system. The display system calibration allowed us to ensure the same, standardized circumstances of examinations. The volumes of all sounds as well as the total surrounding acoustics were evaluated by soundmeter Testo 816. The soundmeter used was previously calibrated using certified acoustic calibrator KA-10. The total surrounding sound level was $65 \pm 3 \mathrm{~dB}$. The volume of the sound stimuli produced by the computer loudspeakers was $75 \mathrm{~dB}$, whereas the level of the old-fashioned landline phone ringtone was $80 \mathrm{~dB}$. All measurements were taken app. $30 \mathrm{~cm}$ from the ears of the examined subjects.

The subjects were instructed before the proper test to hold a push-button manipulator in each hand. Depending on a stimulus category (the color of the figure, the presence of sound, concurrency of the visual and sound stimuli), they had to press the left button, the right one, both of them or to do nothing. In detail, when a green or blue figure was presented, a subject was to press the left-hand button. When a red figure was presented, a subject was to press the right-hand button. When a yellow figure was presented 
or the visual stimulus was presented together with a sound one - the proper reaction was not to press anything. The variety of the stimuli (mixed visual and acoustic ones) as well as reactions determined the nature of the examination as a complex reaction time test.

All tests were held during the same part of the day, between $3.30 \mathrm{pm}$ and $6.00 \mathrm{pm}$. The investigations were carried out in normalized conditions such as the use of the same computer, the same room, identical light, as well as analogous background sounds. Before the tests, the subjects completed a form, stating i.a. their cell phone numbers. As mentioned above, the whole examination consisted of 4 sessions:

1. Training Session (TS) during which the subjects were accustomed with sample stimuli and the use of the application.

2. Control Session (CS) with no telephone ringing during the test.

3. Landline Session (LS) with landline phone ringing.

4. Mobile Session (MS) with mobile phone ringing.

The subjects were not allowed to answer phone calls during the tests and did not know that it was us who called them. The order of sessions 2, 3 and 4 was random, to avoid the subjects getting accustomed to the testing conditions and speed up or improve their reaction. The subjects were instructed not to describe the examination protocol to the subjects still not examined. The first phone call was made in the 60th second of the test; the phone rang for $20 \mathrm{~s}$ and after a 10 -second break it rang again. This cycle was repeated to the end of the test. Finally, an examined subject was exposed to the total of $60 \mathrm{~s}$ of phone ringing, mobile or landline.

The results were subjected to a statistical analysis (Statistica v. 8), including some multidimensional tests. Normal distribution was assessed with the Shapiro-Wilk test. Due to the fact that the distribution of the reaction time results obtained in the male subgroup was not within the norm, a nonparametric multidimensional analysis, Friedman's ANOVA was performed, and the bidimensional analysis of correlations of the studied parameters was checked by means of the nonparametric Wilcoxon test. The statistical significance was set at the level of $\mathrm{p}<0.05$.

\section{RESULTS}

In case of 5 persons, the cell phone either rang during a wrong session (connections not originated by us) or failed to ring at all (for example when the cell phone had

Table 2. Analysis of reaction times in the general group

\begin{tabular}{|c|c|c|c|}
\hline \multirow[b]{2}{*}{ Parameters } & \multicolumn{3}{|c|}{ Reaction time (ms) } \\
\hline & $\begin{array}{l}\text { Control Session } \\
\text { Group } 0 \\
(\mathrm{~N}=42)\end{array}$ & $\begin{array}{l}\text { Landline Session } \\
\text { Group } 1 \\
(\mathrm{~N}=42)\end{array}$ & $\begin{array}{l}\text { Mobile Session } \\
\text { Group } 2 \\
(\mathrm{~N}=42)\end{array}$ \\
\hline Minimum & 488.16 & 465.95 & 453.78 \\
\hline Maximum & 886.79 & 822.25 & 958.28 \\
\hline Median & 621.02 & 642.13 & 665.15 \\
\hline Arithmetic mean & 635.21 & 650.07 & 670.77 \\
\hline Standard deviation & 88.08 & 75.05 & 92.78 \\
\hline Asymmetry coefficient & 0.94 & 0.10 & 0.86 \\
\hline Statistical analysis & \multicolumn{3}{|c|}{$\begin{array}{c}\text { Friedman's ANOVA test: } F=8.94, p<0.05 \\
\text { Wilcoxon test } Z^{0,1}=1.23, p>0.05 ; \text { Wilcoxon test } Z^{0,2}=2.80, p<0.001 \\
\text { Wilcoxon test } Z^{1,2}=1.60, p>0.05\end{array}$} \\
\hline
\end{tabular}


Table 3. Analysis of reaction times in the subgroup of women

\begin{tabular}{|c|c|c|c|}
\hline \multirow[b]{2}{*}{ Parameters } & \multicolumn{3}{|c|}{ Reaction time (ms) } \\
\hline & $\begin{array}{l}\text { Control Session } \\
\text { Group } 0 \\
(\mathrm{~N}=20)\end{array}$ & $\begin{array}{l}\text { Landline Session } \\
\text { Group } 1 \\
(\mathrm{~N}=20)\end{array}$ & $\begin{array}{l}\text { Mobile Session } \\
\text { Group } 2 \\
(\mathrm{~N}=20)\end{array}$ \\
\hline Minimum & 546.00 & 580.28 & 603.10 \\
\hline Maximum & 886.79 & 822.25 & 958.28 \\
\hline Median & 621.017 & 648.737 & 668.325 \\
\hline Arithmetic mean & 652.476 & 672.804 & 708.976 \\
\hline Standard deviation & 93.56 & 76.11 & 102.96 \\
\hline Asymmetry coefficient & 1.94 & 1.18 & 1.77 \\
\hline Statistical analysis & \multicolumn{3}{|c|}{$\begin{array}{l}\text { Friedman's ANOVA test: } F=7.25, p<0.05 \\
\text { st } Z^{0,1}=0.66, p>0.05 ; \text { Wilcoxon test } Z^{0,2}=2.40, p<0.05 \\
\text { Wilcoxon test } Z^{1,2}=1.58, p>0.05\end{array}$} \\
\hline
\end{tabular}

Table 4. Analysis of reaction time in the subgroup of men

\begin{tabular}{|c|c|c|c|}
\hline \multirow[b]{2}{*}{ Parameters } & \multicolumn{3}{|c|}{ Reaction time (ms) } \\
\hline & $\begin{array}{l}\text { Control Session } \\
\text { Group } 0 \\
(\mathrm{~N}=22)\end{array}$ & $\begin{array}{l}\text { Landline Session } \\
\text { Group } 1 \\
(\mathrm{~N}=22)\end{array}$ & $\begin{array}{l}\text { Mobile Session } \\
\text { Group } 2 \\
(\mathrm{~N}=22)\end{array}$ \\
\hline Minimum & 488.16 & 465.95 & 453.78 \\
\hline Maximum & 776.25 & 739.67 & 734.68 \\
\hline Median & 608.950 & 631.028 & 652.392 \\
\hline Arithmetic mean & 619.507 & 629.411 & 636.040 \\
\hline Standard deviation & 84.27 & 71.36 & 71.17 \\
\hline Asymmetry coefficient & 0.50 & -0.45 & -0.75 \\
\hline Statistical analysis & \multicolumn{3}{|c|}{$\begin{array}{l}\text { Friedman's ANOVA test: } F=8.94, p<0.05 \\
\text { est } Z^{0,1}=1.08, p>0.05 ; \text { Wilcoxon test } Z^{0,2}=2,01, p<0.01 \\
\text { Wilcoxon test } Z^{1,2}=0.80, p>0.05\end{array}$} \\
\hline
\end{tabular}

been muted by the subject before the beginning of tests). Those results were not considered for the analysis. Thus, only 20 females and 22 males were included in the analysis. The results were collected in three groups:

- Group 0 - Control Session (CS) results.

- Group 1 - Landline Session (LS) results.

- Group 2 - Mobile Session (MS) results.

The results were distinguished according to the gender of the subjects.

The first statistical analysis concerned all subjects with no gender discrimination. The nonparametric multidimensional test revealed that the reaction time of the subjects influenced by the sound of the ringing mobile phone belonging to them (MS, $665 \mathrm{~ms}$ ) is longer than in the test with the landline phone ringing (LS, $642 \mathrm{~ms}$ ) and the in test not disturbed by any phones (CS, $621 \mathrm{~ms})$. However, the difference was significant $(p<0.05)$ only between the mobile and the control session results. The differences between the subjects in Landline Sessions were not significant in comparison with other sessions $(\mathrm{p}>0.05)$. The detailed results are given in Table 2 and illustrated in Figure 1.

The same results were obtained from the multidimensional analysis of data specific for women. Just as the general group, women showed to have the worst results when 


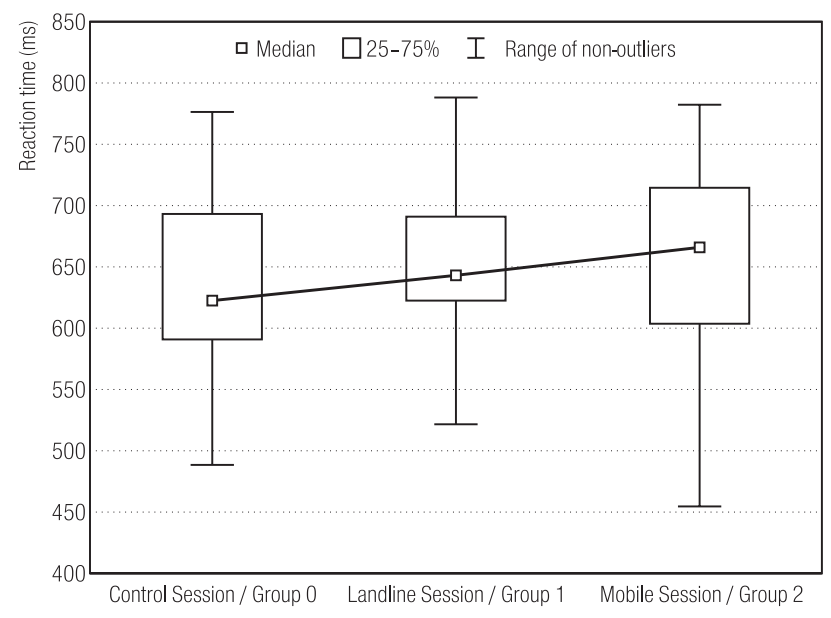

Fig. 1. Analysis of reaction time in the general group

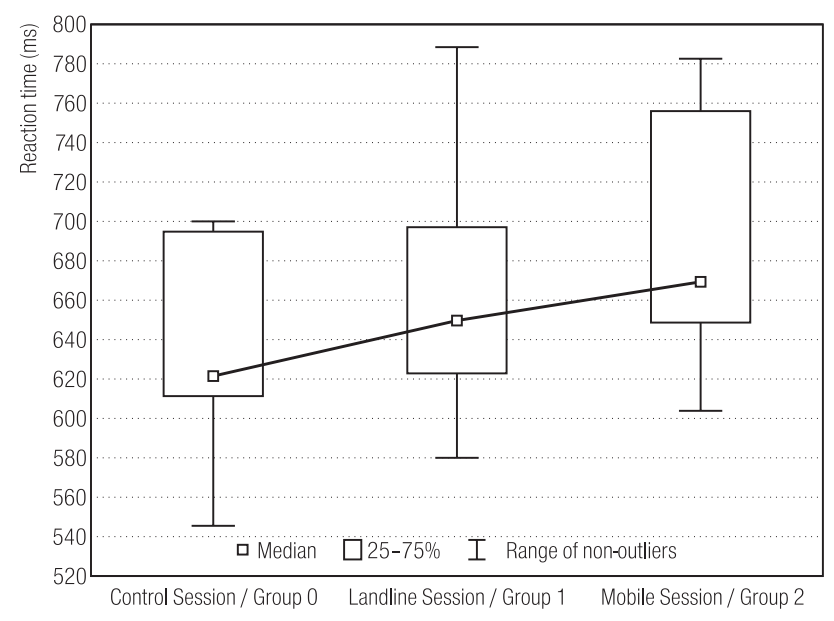

Fig. 2. Analysis of reaction time in the subgroup of women

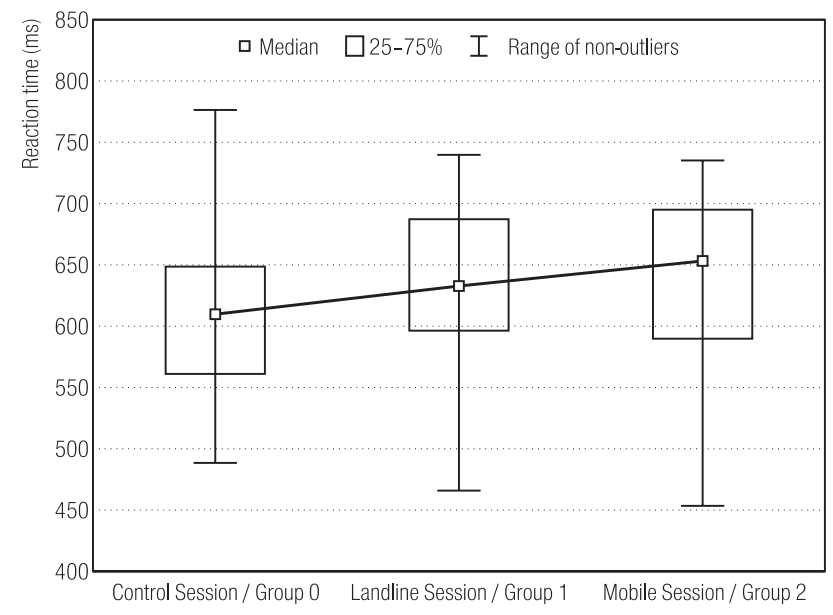

Fig. 3. Analysis of reaction time in the subgroup of men

completing the test being disturbed by their own mobile phone. Similarly, the results of MS reaction time (668 ms) showed to be significantly worse than in the two other groups (LS - $648 \mathrm{~ms}$ and CS - $621 \mathrm{~ms}, \mathrm{p}<0.05$ ). Nevertheless, the difference was significant only between Mobile and Control Sessions $(p<0.05)$. The other differences, showed in detail in Table 3, proved not to be significant $(p>0.05)$. The graphical presentation of the results is given in Figure 2.

The results described above were obtained also in the subgroup of men. The only significant difference appeared in the multidimensional analysis that concerned Mobile

Table 5. Analysis of reaction time according to the gender of the subjects

\begin{tabular}{lcccccc}
\hline & \multicolumn{5}{c}{ Reaction time $(\mathrm{ms})$} \\
\cline { 2 - 6 } \multicolumn{1}{c}{ Parameters } & \multicolumn{2}{c}{ Control Session } & \multicolumn{2}{c}{ Landline Session } & \multicolumn{2}{c}{$\begin{array}{c}\text { Mobile Session } \\
\text { Group 2 }\end{array}$} \\
\cline { 2 - 7 } & Group 0 & Group 1 & women & men & women & men \\
& $(\mathrm{N}=20)$ & $(\mathrm{N}=22)$ & $(\mathrm{N}=20)$ & $(\mathrm{N}=22)$ & $(\mathrm{N}=20)$ & $(\mathrm{N}=22)$ \\
\hline Minimum & 546.00 & 488.16 & 580.28 & 465.95 & 603.10 & 453.78 \\
Maximum & 886.79 & 776.25 & 822.25 & 739.67 & 958.28 & 734.68 \\
Median & 621.017 & 608.950 & 648.737 & 631.028 & 668.325 & 652.392 \\
Arithmetic mean & 652.476 & 619.507 & 672.804 & 629.411 & 708.976 & 636.040 \\
Standard deviation & 93.56 & 84.27 & 76.11 & 71.36 & 102.96 & 71.17 \\
Asymmetry coefficient & 1.94 & 0.50 & 1.18 & -0.45 & 1.77 & -0.75 \\
Statistical analysis & Test $\mathrm{Z}_{\text {Mann-Whitney }}=-0.81, \mathrm{p}>0.05$ & Test $\mathrm{Z}_{\text {Mann-Whitney }}=-1.22, \mathrm{p}>0.05$ & Test $\mathrm{Z}_{\text {Mann-Whitney }}=1.77, \mathrm{p}>0.05$ \\
\hline
\end{tabular}


Session (652 ms) and Control Session (610 ms) $-\mathrm{p}<0.01$. All other differences noted in the analysis of men were not significant $(\mathrm{p}>0.05)$. The detailed data are collected in Table 4 and illustrated in Figure 3.

We also tried to compare separately reaction time results recorded in every Session according to the gender of the subjects. Women showed worse reaction times in all Sessions comparing to men. However, it should be emphasized that no difference appeared to be significant $(p>0.05)$. The detailed data are shown in Table 5.

\section{DISCUSSION}

One of the most common examples of human activity involving and demanding good quality of attention, concentration as well as reaction time is car driving. Due to the dissemination of vehicles as means of transport, the problem of traffic accidents is gaining greater and greater significance. It is estimated that only in Poland 504598 traffic accidents occurred in 2000-2009, with 55286 fatalities. The gross domestic product of Poland diminished in the mentioned period by $2.5 \%$ [6]. Although the statistics look better in other European countries, the problem still needs efforts and legal solutions. Due to that, it is no wonder that any activity that could contribute to reducing the above-mentioned disastrous results would be of value. Probably this is the reason why a ban on using hand-held mobile phones while driving is widely introduced and accepted all over the world. Some governments go even further in their legislations prohibiting the use of the mobiles with hands free sets or in GPS functions (Massachusetts, USA).

It can be clearly seen that the problem of impacting the human psychomotoric abilities by various aspects of mobile phones usage is still vivid and explored by numerous authors. It is obvious that when the problem concerns drivers, the conditions should imitate the car cockpit. Irwin et al. studied 16 adults depressing the break pedal while being influenced by 5 different factors [7]. A similar study was performed by Consiglio et al. who revealed the elongation of reaction time due to cellular phone conversation [8]. These studies were carried out in laboratory conditions using models resembling a car cockpit and imitating well the conditions of natural road traffic. Other authors focus their attention on some specific aspects of mobile phone use, which sometimes demands specialized laboratory equipment. Barkana examined the visual field of the subjects conducting the hands-free conversation on their cellular phones [9]. Ishigami at al. concluded in their review that performance, when using the hands-free phone, is in fact not better than when using a hand-held one [10]. The quoted papers indicate clearly that a phone conversation impairs sensomotoric activities. This impairment is complex and indicates the involvement of the central nervous system. It leads to decreasing visual ability [9] or speed of performing the movements necessary for braking [7,8].

It is intuitively obvious that one becomes accustomed to the ringtone of their phone, which in turn impacts the current activity, regardless of the character of this activity. It seems to be natural to be curious to know who is calling, curious enough to distract oneself and diminish one's psychomotor ability and concentration. It applies not only to drivers, but to all humans performing attention-demanding tasks. Due to that, we decided to check whether the sound of one's mobile phone reduces their complex reaction time achievements and if the old-fashioned landline phone ringtone impacts the human attention in the same degree.

In our study, we noted that both ringtones, of mobile and landline phones, elongated the subjects' reaction times. However, the elongation was statistically significant only in the subjects exposed to the influence of mobile phone ringing $(p<0.01$ and $p<0.05)$. We concluded that the familiar sound (cell phone) focuses much more attention of a human than a more neutral sound (landline phone). It 
is natural to check who is calling, so we strive to reach for the phone and answer the call. In our opinion, although this reflex is inhibited by intentional decisions and objective factors, it can result in dangerous reduction of attention and ability to react properly and early enough in demanding situations. The phone ringtone seems to trigger additional thoughts about the caller and, when considered in general, results in diverting our attention from the current activities. The results confirm these considerations and may provide additional argument in the discussion about using cell phones while driving or conducting other activities that require concentration and full psychomotor performance.

In our previous study we examined the isolated mobile phone sound impact on the reaction time of human beings [5]. The findings of the quoted study confirm our present results concerning the destructive influence of the ringing mobile phone on the human reaction time. In the current paper we found the differences between reaction times noted in cell phone sessions vs. control sessions to be statistically significant for all the tested subjects as a whole $(Z=2.8, p<0.001)$, as well as for both the male group $(Z=2.01, p<0.01)$ and the female group $(Z=2.4$, $\mathrm{p}<0.05)$.

We recorded longer reaction times in the female group in comparison with the male one, but it should be pointed out that the differences were not statistically significant $(p>0.05)$. This lack of significant discrepancies could be seen in all three sessions: Control Session, Landline Session and Mobile Session. On the other hand, the fact of existence of gender-related differences is consistent with the outcome of our two previous researches, in which women had proven to have a statistically significant longer reaction time than men while performing the same task $[4,5]$. This aspect was also considered in studies by other authors. The differences in reaction time during a phone conversation were examined, however no relation to gender was proven $[7,8]$. This might be related to brain lateralization being differently expressed in both sexes [11-14]. Stalans and Wedding concluded that a faster response observed in men is due to the great extent of cerebral lateralization [11]. Davidson et al. proved in their two experiments described in the quoted paper that female brains are less lateralized than male ones [12]. Watson showed in his hand accuracy test gender-related tendency of men to get better results [13]. Bell found greater functional magnetic resonance imaging (fMRI) activity in men performing three cognitive tasks [14]. In our opinion, the phenomenon of gender-related differences in reaction time could be explained more clearly by conducting the dedicated study based upon a much more numerous population. Due to the lack of significant differences in the current study we can only refer to literature data and results of our previous works.

In the available literature we found no studies describing the experiments testing the effect of mobile phone ringing on the overall performance or complex reaction time. It is therefore difficult to compare the obtained results with corresponding findings of other authors. The mobile phone ringtones are characterized by a wide variety of types, frequencies, and differentiating parameters. We believe that the strength of one's reaction and the extent of attention change are dependent on some sound parameters that have not been identified yet. The neuro-physiological background of the elongation of reaction time in both situations, when using a mobile phone or just hearing it ringing, still remains unclear [12]. Some authors pointed to the negative effects of electromagnetic radiation emitted by phones on the pre-attentive information processing in the tested subjects [15]. Although the neurological basis of the observed phenomena seems to be complex, it can be pointed out that some processes are not involved. Bak et al. revealed that commonly used mobile phones do not affect the propagation of electrical stimuli along the auditory nerve to auditory brainstem centers [16]. Parazzini et al. revealed that short-term Universal Mobile 
Telecommunications System (UMTS) exposure has no effect on the human auditory system [17]. These findings indicate that the mobile phone activity, resulting in RT elongation, impacts other brain structures than the auditory system.

In the past, old-fashioned phones had almost unified ringtones. Moreover, they were not 'personal' in the present meaning of that word. They were similar and common enough to induce a kind of psychosocial 'tolerance' - the phone could not be 'personalized'. It is only now that varying ringtones distinguish our 'very own' property and allow us to pick our private phone out in the crowd of everyday sounds. Some authors have already focused on the importance of distinctive parameters of sounds. Suied evaluated the influence of some acoustic parameters on reaction time [18]. Edworthy et al. [19], suggested that improvement of existing auditory warning systems can be done by 'fitting' some acoustic parameters to specific needs. We wonder if 'fitting' ringtones of mobile phones could contribute to the improvement of better perception and avoidance of attention attenuation. An undertaking of a study dedicated to this problem could be of value. Quite interesting findings of Graham [20], who revealed that auditory icons produced significantly faster reaction times than the conventional (visual) warnings, can be explained by our own finding that auditory signals, due to different brain processing, are generally quicker recognized that visual ones [9]. What is more important, Graham admits that optimal warnings could be achieved by adjusting certain sound attributes of auditory icons. We find this observation to be a one more 'pro' for ringtones processing and reengineering.

\section{ACKNOWLEDGEMENTS}

This is to certify that the first and second author of this paper contributed equally to its origin and their authorship should be treated as equal.

\section{REFERENCES}

1. Törnros J. Effect of driving speed on reaction time during motorway driving. Accid Anal Prev 1995;27(4):435-42.

2. Miettinen I, Tiitinen H, Alku P, May PJ. Sensitivity of the human auditory cortex to acoustic degradation of speech and non-speech sounds. BMC Neurosci 2010;11:24.

3. Cavanagh P, Alvarez GA. Tracking multiple targets with multifocal attention. Trends Cogn Sci 2005;9(7):349-54.

4. Zajdel R, Nowak D. Simple and complex reaction time measurement. A preliminary evaluation of new approach and diagnostic tool. Comput Biol Med 2007;37(12):1724-30.

5. Zajdel R, Zajdel J, Zwolińska A, Śmigielski J, Beling P, Cegliński $\mathrm{T}$, et al. The sound of a mobile phone ringing affects the complex reaction time of its owner. Arch Med Sci. In Press 2012. DOI: 10.5114/aoms.2012.28891.

6. Najwyższa Izba Kontroli (NIK), Departament Komunikacji i Systemów Transportowych. Information about the results of traffic safety control in Poland. Reg. No. 5/2011/P/10/061/ KKT. Warszawa: NIK; 2011 [cited 2011 Dec 20]. Available from URL: http://www.patronat.pl/aktualnosci/2011/jpg/ nik\%202011\%20o\%20brd.pdf [in Polish].

7. Irwin M, Fitzgerald C, Berg WP. Effect of the intensity of wireless telephone conversations on reaction time in a braking response. Percept Mot Skills 2000;90(3 Pt 2):1130-4.

8. Consiglio W, Driscoll P, Witte M, Berg WP. Effect of cellular telephone conversations and other potential interference on reaction time in a braking response. Accid Anal Prev 2003;35(4):495-500.

9. Barkana Y, Zadok D, Morad Y, Avni I. Visual field attention is reduced by concomitant hands-free conversation on a cellular telephone. Am J Ophthalmol 2004;138(3):347-53.

10. Ishigami Y, Klein RM. Is a hands-free phone safer than a handheld phone? J Safety Res 2009;40(2):157-64.

11. Stalans L, Wedding D. Superiority of the left hemisphere in the recognition of emotional faces. Int J Neurosci 1985;25(3-4): 219-23.

12. Davidson H, Cave KR, Sellner D. Differences in visual attention and task interference between males and 
females reflect differences in brain laterality. Neuropsychologia 2000;38(4):508-19.

13. Watson NV, Kimura D. Right-hand superiority for throwing but not for intercepting. Neuropsychologia 1989;27(11-12): 1399-414.

14. Bell EC, Willson MC, Wilman AH, Dave S, Silverstone PH. Males and females differ in brain activation during cognitive tasks. Neuroimage 2006;30(2):529-38.

15. Papageorgiou CC, Nanou ED, Tsiafakis VG, Kapareliotis E, Kontoangelos KA, Capsalis CN, et al. Acute mobile phone effects on pre-attentive operation. Neurosci Lett 2006;397(1-2): 99-103.

16. Bąk M, Śliwińska-Kowalska M, Zmyślony M, Dudarewicz A. No effects of acute exposure to the electromagnetic field emitted by mobile phones on brainstem auditory potentials in young volunteers. Int J Occup Med Environ Health 2003;16(3):201-8. 17. Parazzini M, Lutman ME, Moulin A, Barnel C, ŚliwińskaKowalska M, Zmyślony M, et al. Absence of short-term effects of UMTS exposure on the human auditory system. Radiat Res 2010;173(1):91-7.

18. Suied C, Susin, P, McAdams S. Evaluating warning sound urgency with reaction times. J Exp Psychol 2008;14:201-12.

19. Edworthy J, Loxle, S, Dennis I. Improving auditory warning design: Relationship between warning sound parameters and perceived urgency. Hum Factors 1991;33:205-31.

20. Graham R. Use of auditory icons as emergency warnings: evaluation within a vehicle collision avoidance application. Ergonomics 1999;42(9):1233-48.

This work is available in Open Access model and licensed under a Creative Commons Attribution-NonCommercial 3.0 Poland License - http://creativecommons.org/ licenses/by-nc/3.0/pl/deed.en. 